\title{
Capsule Commentary on Kalkhoran et al., Patterns of and Reasons for Electronic Cigarette Use in Primary Care Patients
}

\author{
Ellie Grossman, $M D M P H^{1,2}$ \\ 'Department of Medicine, Harvard Medical School, Boston, MA, USA; '2Department of Medicine, Cambridge Health Alliance, Cambridge, USA.
}

J Gen Intern Med 32(10): 1135

DOI: $10.1007 / \mathrm{s} 11606-017-4131-\mathrm{x}$

(c) Society of General Internal Medicine 2017

$\mathrm{T}$ he study by Kalkhoran et al. ${ }^{1}$ uses data from a smokingcessation trial to describe e-cigarette use among primary care patients. The study participants were recruited from patients in three primary care practices in San Francisco who were enrolled in a test of a tablet-based intervention. At baseline, they were asked questions about their use of ecigarettes and reasons for doing so. Of the 788 participants, $52 \%$ reported they had ever used an e-cigarette and $20 \%$ had used one in the last month. E-cigarette users tended to be younger than non-users, and use was least prevalent at the safety-net general internal medicine practice. Only $9 \%$ of current e-cigarette users reported using them daily, and $66 \%$ had used them on $\leq 5$ days in the past month. Most e-cigarette users did not know the nicotine content of their devices; seeking assistance in cutting down or quitting conventional cigarettes and reducing harm were the most common reasons for use.

In sum, although the study was limited to one West Coast city, these results are similar to other studies describing e-cigarette use in the general U.S. population. $^{2}$ The vast majority of e-cigarette users also smoke (or have smoked) conventional cigarettes, so this population is a reasonable one for focus. On a practical level, clinicians and health-care systems who ask about ecigarette use may uncover a population of smokers who want to quit, and this may open a discussion of evidence-based tools that can help (i.e. not necessarily e-cigarettes).

The perception of e-cigarettes as less harmful than conventional cigarettes demonstrates how powerful marketing and media can be, and should serve as a note of caution both for this product and for others to come. It was not until recently that we had solid evidence comparing e-cigarettes to conventional cigarettes in terms of carcinogen or toxin exposure, ${ }^{3}$ and yet e-cigarette marketers were able to strongly impress upon the public that these devices were safer than conventional cigarettes. The use of such devices has skyrocketed in the U.S., and public-health messaging has been somewhat slow to solidify; we owe it to our patients to discuss both ecigarettes and conventional cigarettes routinely.

Corresponding Author: Ellie Grossman, MD MPH; Department of Medicine, Cambridge Health Alliance, Cambridge, USA (e-mail: egrossman@challiance.org).

\section{Compliance with Ethical Standards:}

Conflict of Interest: The author has no conflicts of interest with this article.

\section{REFERENCES}

1. Kalkhoran S, Alvarado N, Vijayaraghavan M, et al. Patterns of and reasons for electronic cigarette use in primary care patients. J Gen Intern Med. 2017. doi:10.1007/s11606-017-4123-x.

2. Schoenborn CA, Gindi RM. Electronic cigarette use among adults: United States, 2014. NCHS Data Brief 217. Hyattsville, MD: National Center for Health Statistics; 2015.

3. Shahab L, Goniewicz ML, Blount BC, et al. Nicotine, carcinogen, and toxin exposure in long-term e-cigarette and nicotine replacement therapy users: a cross-sectional study. Ann Intern Med. 2017;166(6):390-400. 